\title{
Nucleic-Acid Based Lateral Flow Strip Biosensor via Competitive Binding for Possible Dengue Detection
}

\author{
Henson L. Lee Yu' ${ }^{1}$, Christine Marie Montesa ${ }^{2}$, Nina Rosario L. Rojas ${ }^{1}$ and Erwin P. Enriquez ${ }^{1 *}$ \\ ${ }^{1}$ Department of Chemistry, Ateneo de Manila University, Quezon City, Philippines \\ 2JEOL Asia Ltd., Corporation Place, Singapore
}

\begin{abstract}
A low-cost, simple, rapid and selective nucleic-acid based lateral flow strip biosensor (LFSB) for possible dengue viral RNA detection is described in this study. The detection is based on competitive binding, where gold nanoparticles (AuNPs), with average size of $\sim 10 \mathrm{~nm}$ confirmed using UV-Vis, TEM and AFM images, are used as visualizing agents. These are bioconjugated with DNA which competitively binds with its complementary strand either in the sample or in the test line of the LFSB. The detection scheme reduces the number of probes which effectively lowers the cost for the design of the test strip. The whole test took less than five minutes to complete and a red line signifies a negative result, while the absence of the line signifies a positive result. Quantification of the intensity of the red band reveals proportionality of the color to the amount of DNA present in the sample. The visual limit of detection of the LFSB is $10^{-7} \mathrm{M}$. It demonstrates selectivity in a blood matrix and selectivity over a synthetic Influenza. This study brings us closer to an amplification-free, point-of-care method for dengue detection.
\end{abstract}

Keywords: Lateral flow strip biosensor; Dengue detection; Gold nanoparticles; Competitive binding assay

\section{Introduction}

A lateral flow strip biosensor (LFSB) is a type of sensor in which the elements are arranged in a strip of membrane and a test sample is allowed to elute through the membrane. The interpretation of the results will vary depending on the signal transduction mechanism. LFSB's are gaining more attention as a detection platform because they are easy-to-use, rapid, and amenable to point-of-care testing. This allows for a test that requires minimal technical expertise to interpret the results [1].

LFSB may be used to detect various targets including nucleic acids $[2,3]$, proteins [4], bacteria $[5,6]$ and small organic compounds $[7,8]$, among others. Most common forms of LFSB use gold nanoparticles conjugated to the antibody of the analyte to be studied, and a secondary antibody immobilized into the test strip to give a characteristic red band if the analyte is detected. Gold nanoparticles are often used because of the ease of modification and bioconjugation to different biomolecules, and its high extinction coefficient [9]. Depending on the antibody attached to the gold nanoparticles, the LFSB format has been used in several applications including bacterial and viral infections such as Citrus tristeza virus in plants, leptospirosis, rotavirus, hepatitis B and C virus. [10].

For this study, nucleic acids are used as a target and dengue is chosen to be the initial application because there has been no reported nucleic-acid based lateral flow strip biosensor for dengue, and dengue fever is rampant in the Philippines. The World Health Organization (WHO) has estimated that some 50-100 million are affected by this disease in a year and 20,000 died from the disease in its report in 2004. Dengue is one of the most widely spread mosquito-borne disease. Early diagnosis of the disease is one of the key ways to address this concern; however, this remains a challenge because of the similar symptoms at the onset of the disease. Thus, there is a need for a simple, rapid, and low cost detection for dengue. Also, for viral infections, the virus RNA appears at the onset of the disease, and this is important for early detection. Previous studies on the detection of dengue include detection via electrochemiluminescence [11], RNA amplification via reverse-transcription polymerase chain reaction (RT-PCR) [12,13], nucleic-acid sequence based amplification (NASBA) $[13,14]$ and reverse-transcription loop-mediated isothermal amplification (RTLAMP) [15] or antigen-antibody based dipstick biosensor [16,17]. Another reason why RNA is used as the target biomarker is that there is a high correlation between febrile phase and the viraemia titer in a patient with dengue $(p<0.001)$ [18]. This means that, during the febrile period, i.e., when the patient has fever, the amount of dengue viral RNA is also at its peak.

To the best of the knowledge of the authors, there has been no reported nucleic acid-based LFSB specific to dengue virus based on competitive binding assay. This study explores how LFSB is used to detect viral RNA in blood samples. The LFSB used in this study consists of a strip of nitrocellulose membrane, a specific nucleic acid sequence dried and immobilized to a region on the membrane called a test line, and gold nanoparticles (AuNP) covalently attached to a strand of nucleic acid with a sequence complementary to the one in the test line. The complementary nucleic acid sequence gives a molecular signal if the viral RNA is present or not, and the gold nanoparticles convert the molecular signal, which in this case is the hybridization of the complementary strands, to a visually-detectable response. A schematic diagram of how this biosensor works is found in figure 1 .

As a proof of principle, the biosensor described in the present work is a prototype and uses synthetic dengue DNA. The sequence of the DNA probe used (i.e., the DNA conjugated to the gold nanoparticles) is adapted from the study of Baeumner et al. [5]. The same 21-mer probe has been used to detect dengue viral RNA in three other studies $[11,13,19]$. Further work has to be done on improvement of the sensitivity by

${ }^{*}$ Corresponding author: Erwin P. Enriquez, Department of Chemistry, Ateneo de Manila University, Quezon City, Philippines, E-mail: epenriquez@ateneo.edu

Received October 30, 2012; Accepted November 08, 2012; Published November 10,2012

Citation: Yu HLL, Montesa CM, Rojas NRL, Enriquez EP (2012) Nucleic-Acid Based Lateral Flow Strip Biosensor via Competitive Binding for Possible Dengue Detection. J Biosens Bioelectron 3:128. doi:10.4172/2155-6210.1000128

Copyright: $\odot 2012$ Yu HLL, et al. This is an open-access article distributed under the terms of the Creative Commons Attribution License, which permits unrestricted use, distribution, and reproduction in any medium, provided the original author and source are credited. 


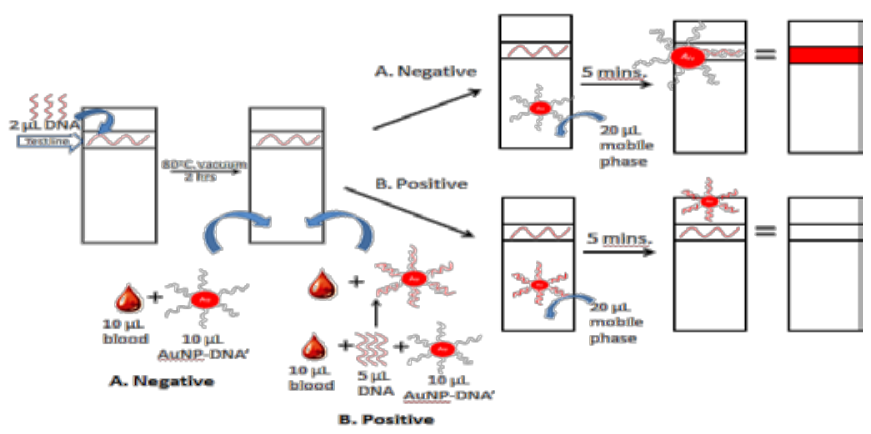

Figure 1: Schematics of the LFSB fabricated in the study. First, $2 \mu \mathrm{L}$ of a DNA sequence is dropped onto the membrane and the strip is vacuum dried at $80^{\circ} \mathrm{C}$ for two hours to immobilize the DNA on a region called the test line. Then, for a negative control, gold nanoparticles (AuNP) conjugated with DNA (sequence complementary to the strand immobilized to the test line) in a blood sample without a synthetic target DNA (sequence similar to the strand immobilized to the test strip) were added to the membrane. Upon the addition of an eluent buffer as the mobile phase, the AuNP-DNA bound with the previously immobilized DNA in the test line forms a red band. For a positive control, a second aliquot of AuNP-DNA was added to a blood sample with synthetic target DNA and this hybridized with AuNP-DNA. This time, upon the addition of the eluent buffer, there was no free conjugated DNA that can bind to the DNA in the test line, so no red band was formed.

adding other visualizing agents and other preconcentration techniques in order to reach the reported levels of dengue viral RNA in blood (approximately 10-11-10-15 M) [20].

\section{Materials and Methodology}

\section{Apparatus}

Shimadzu UV-2401 PC UV-Vis Spectrophotometer, Shimadzu IRAffinity-1 Fourier Transfer Infrared Spectrophotometer, Park Scientific XE-70 Atomic Force Microscope, JEOL Transmission Electron Microscope, and Epson ME Office $620 \mathrm{~F}$ scanner were used.

\section{Materials}

Hydrogen tetrachloroaurate (III), Bovine Serum Albumin (BSA), were purchased from Sigma-Aldrich. Sodium borohydride, monobasic and dibasic sodium phosphate, sodium chloride, sucrose and Ethylenediaminetetraacetic Acid (EDTA) were obtained from JT Baker. Sodium citrate and sodium hydroxide were purchased from Merck. Tween-20 was purchased from APS Chemicals Ltd. UniSart CN140 (polyester backed) was given by Sartorius. The probes used and deoxyadenosine triphosphate (dATP) were obtained from invitrogen, and the sequences of the probes are as follows: Sequence 1 (Capture probe/Complementary to target DNA): 5'-thiol-AAA CAG CAT ATT GAC GCT GGG 3', Sequence 2 (Target DNA): 5' CCC AGC GTC AAT ATG CTG TTT 3', Sequence 3 (Mismatch): 5' CTT CTA ACC GAG GTC GAA ACG 3'.

\section{Synthesis of AuNP}

The synthesis route is adapted from Martin et al. [21]. A mixture of $0.50 \mathrm{mM} \mathrm{HAuCl}_{4}$ and $0.50 \mathrm{mM} \mathrm{HCl}$ solution was placed in a glass vial with a total volume of $10 \mathrm{~mL}$. The solution was mixed using a vortex mixer and a $300 \mu \mathrm{L}$ solution of $0.50 \mathrm{mM} \mathrm{NaBH}_{4}$ and $0.50 \mathrm{mM}$ $\mathrm{NaOH}$ were added all at once. The solution turned from light yellow to bright red-orange solution almost instantaneously. The solution was continually mixed for one more minute, and then heated for 3 minutes until just before boiling [21]. The solution was allowed to cool to around room temperature and passed through a membrane filter with pore size of $0.45 \mu \mathrm{m}$ to remove coagulated particles. The AuNP solution was stored at $4^{\circ} \mathrm{C}$ for future use.

\section{Bioconjugation and characterization of AuNP to DNA sequence}

AuNP was conjugated to thiolated DNA (DNA-SH) according to the following procedure [22]. First, a solution of $100 \mathrm{mM}$ dATP was added to the AuNP synthesized from above in a 300:1 mole ratio. Then, the solution was allowed to equilibrate at room temperature for 15 minutes. $10 \mathrm{mM}$ PBS (0.1 M NaCl), and DNA (30:1 mole ratio) were added to the solution and was allowed to equilibrate at $60^{\circ} \mathrm{C}$. The AuNP-dATP solution was also heated to $60^{\circ} \mathrm{C}$ for comparison. After heating for 3 hours, the solution was washed three times with $10 \mathrm{mM} \mathrm{PBS}, 0.1 \mathrm{M} \mathrm{NaCl}$ solution and redispersed for storage in $10 \mathrm{mM}$ PBS, $0.3 \mathrm{M} \mathrm{NaCl}$ solution. UV-Vis spectra were obtained after the synthesis and bioconjugation of AuNP-DNA. Particle size distribution and crystallinity of AuNP were confirmed by TEM and AFM. The hybridization of AuNP-DNA was verified using UV-Vis Spectrophotometer.

\section{Assembly of the LFSB}

A solution of DNA was manually striped onto a specific part of the nitrocellulose membrane by repeatedly adding small amounts of DNA using a gel pipette tip and allowed to dry. The strip was heated in a vacuum oven at $80^{\circ} \mathrm{C}$ for two hours to prevent it from eluting with the mobile phase. A small strip of absorbent pad was also placed above the nitrocellulose membrane with a few millimeters overlap to help wick the mobile phase.

\section{Hybridization experiment}

An aliquot of the AuNP-DNA solution was dropped a few millimeters from one end of the membrane and allowed to dry. Once dry, $20 \mu \mathrm{L}$ of the desired mobile phase was dropped onto the end of the membrane to carry the AuNP-DNA conjugate across the membrane. For the control experiment, a solution of AuNP was dropped onto the membrane. For the "negative" test, a solution of AuNP-DNA was added to the membrane. For the "positive" test, a solution of AuNP-DNA was added to the membrane and various concentrations of the target DNA (probe 2) was spiked to the mobile phase. After a picture of the membrane was scanned, the image was processed using Quantiscan ${ }^{\circ}$ (Biosoft). A histogram was generated showing the intensity of the peak versus the distance from the dipstick. The height of the desired peak is automatically generated using the program.

\section{Optimization and selectivity studies}

Different concentrations of capture DNA were immobilized onto the membrane using a pipette tip. Four strips were immobilized with $1000,500,50$ and 5 pmol of the capture probe and equal amounts of AuNP-DNA was used. The resulting bands were quantified using Quantiscan ${ }^{\circ}$. Also, different concentrations of the target DNA were spiked to the AuNP-DNA solution. $5 \mu \mathrm{L}$ of a solution containing $10^{-4}$, $10^{-5}, 10^{-6}, 10^{-7}, 10^{-8}$, and $10^{-9}$ of the target DNA was used to determine the limit of detection of the study and PBS buffer was used as a control. The generated peaks from QuantiScan data were also graphed. Then, the mobile phase was changed to a whole blood sample to study its selectivity in the actual matrix. $10 \mu \mathrm{L}$ of blood is added to $10 \mu \mathrm{L}$ of AuNP then spiked with $5 \mathrm{uL}$ of the desired target DNA concentration (same as above). To study the sequence specificity of the method, a $10^{-4} \mathrm{M}$ solution of mismatch DNA (specifically that with the sequence of the Influenza A virus) was added to study its selectivity against the common flu virus. All experiments were done at least in triplicate using 


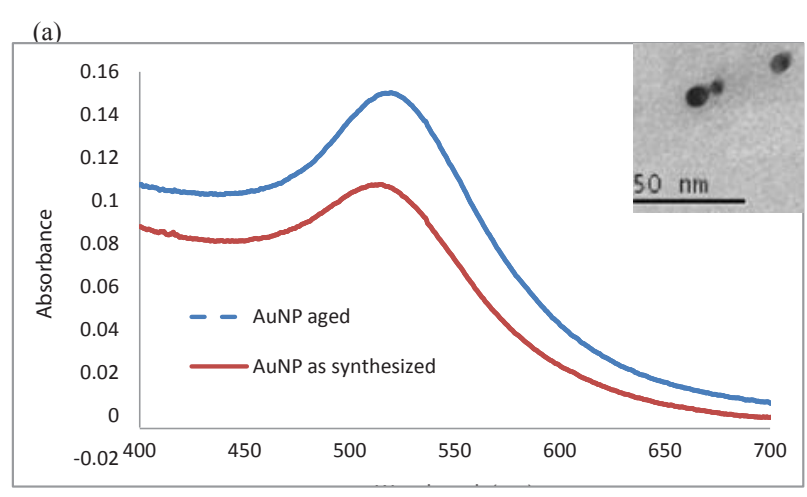

(b)

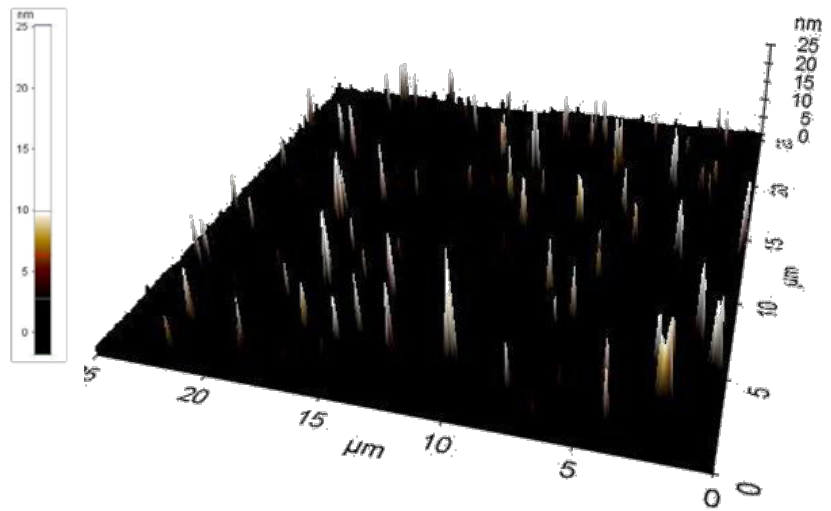

Figure 2: Characterization of the synthesized AuNP. (a) UV-Vis spectra of as synthesized (solid line) AuNP $(\lambda=515 \mathrm{~nm}$ ) and aged gold nanoparticles (dashed line) for 5 months $(\lambda=519 \mathrm{~nm})$. (inset shows TEM image of AuNP. (b) 3D AFM image of the synthesized gold nanoparticles showing the size distribution. Colors of peaks relate to the sizes: white $(>10 \mathrm{~nm})$, yellow $(7-10$ $\mathrm{nm})$, red $(4-6 \mathrm{~nm})$, and black $(<4 \mathrm{~nm})$

different batches of synthesized AuNP and AuNP-DNA to verify the reproducibility and repeatability of the results.

\section{Results and Discussion}

\section{Synthesis of gold nanoparticle probe}

The gold nanoparticles were characterized by their UV-Vis absorption. The UV-Vis spectrum is shown in figure 2a. The AuNP was approximately $10 \mathrm{~nm}$ as indicated by its $\lambda_{\max }$ of $517 \mathrm{~nm}$ [23]. An AFM image figure $2 \mathrm{~b}$ shows the polydispersity of the particle sizes, ranging from $4 \mathrm{~nm}$ to $13 \mathrm{~nm}$, averaging at around $10 \mathrm{~nm}$. This was also confirmed via TEM as shown in the inset in figure 2a. The AuNP synthesized are reasonably stable as shown by only a slight shift in $\lambda_{\max }$ $(\sim 2 \mathrm{~nm})$ even after five months; and a slight broadening of the peak indicates some polydispersity of the sizes of the gold nanoparticles. Despite the changes in $\lambda_{\max }$ and peak width, the gold nanoparticles still flowed through the nitrocellulose membrane, which means they were not aggregated and still small enough and to flow through the membrane, which is desirable for the study.

In synthesizing the AuNP-DNA conjugate, the AuNP was first weakly bound to dATP before the addition of thiolated DNA. When AuNP-dATP was heated to $60^{\circ} \mathrm{C}$ in the presence of thiolated DNA (DNA-SH), AuNP-DNA-SH will be preferentially formed because of the strong covalent interaction between $\mathrm{Au}$ and sulfur. If AuNP was heated without dATP, the color changed from red to purple indicating aggregated larger particles. The UV-Vis spectra of the solution with dATP and without dATP are compared in figure 3a. For the solution without DNA, the absorbance at 520-600 $\mathrm{nm}$ indicated flocculation into various sizes, while the peak at $255 \mathrm{~nm}$ corresponds to the DNA attached to the AuNP. In figure 3b, the spectrum of a second batch of AuNP-DNA synthesized is compared in the supernatant after washing the nanoparticles with the appropriate buffer. The shift in the peak from $260 \mathrm{~nm}$ in the supernatant (corresponding to free DNA) to $256 \mathrm{~nm}$ in the AuNP-DNA confirms the bioconjugation.

Another purpose of the dATP is to act as "spacers" so that there will be less DNA attached to a single AuNP cluster [21]. This is important because if the AuNP is too crowded with DNA, this lowers the opportunity for the complementary strand to bind. Also, for competitive binding assay applications, it is preferred to have low DNA density per AuNP cluster because this would mean greater sensitivity and lower detection limit. If there are too many DNA molecules attached to an AuNP cluster, even if some competitively binds to the target complementary DNA in the sample, there will still be free DNA strands that will bind to the test line giving a false negative result. In order to estimate the amount of DNA per AuNP, the concentration of the DNA is made to be in excess to the amount of AuNP (calculated using the extinction coefficient in the study of Oh et al. [24]). The maximum number of strands for a $\sim 10 \mathrm{~nm}$ AuNP is around 80 strands [25] because DNA is negatively charged and two DNA strands will repel each other if they are too close. The actual amount of DNA strands

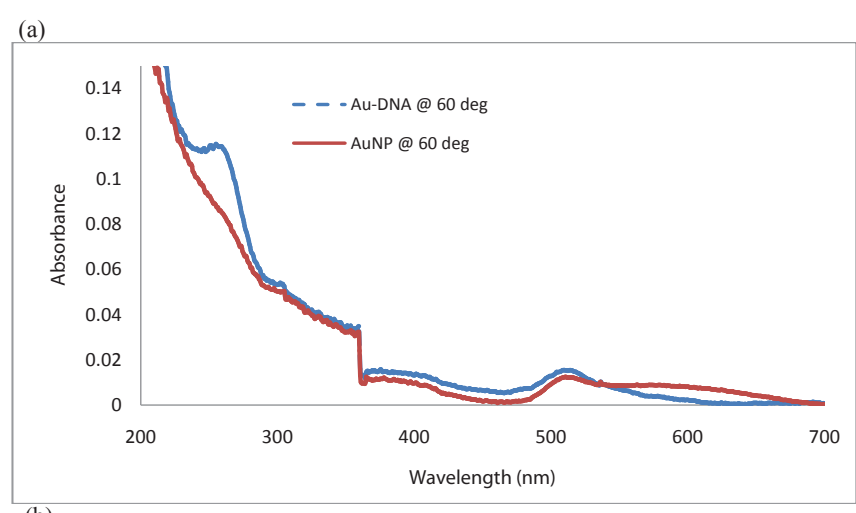

(b)

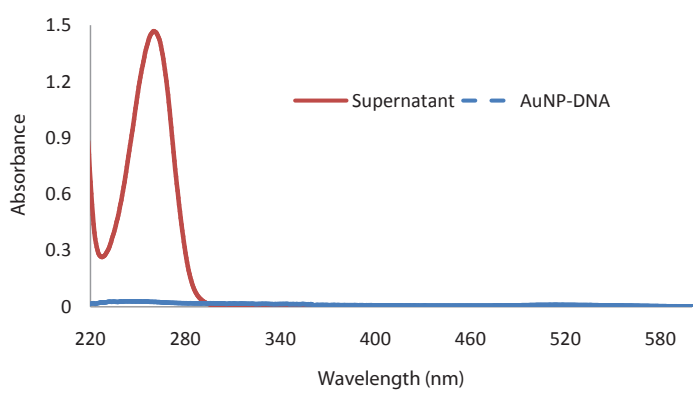

Figure 3: Characterization of AuNP-DNA conjugate. (a) UV-Vis spectra of AuNP-DNA showing $\lambda_{\max }=255 \mathrm{~nm}$ for DNA and $519 \mathrm{~nm}$ for AuNP (dashed line) and AuNP after heating at $60^{\circ} \mathrm{C}$ showing a broad peak at $520-600 \mathrm{~nm}$, indicating flocculation (solid line). (b) UV-Vis spectra of the AuNP-DNA compared (dashed line) to that of the supernatant (solid line) after bioconjugation. The $\lambda$ max corresponding to the DNA shifted from $260 \mathrm{~nm}$ (unbound) to $255 \mathrm{~nm}$ (bound) when conjugated to AuNP. The AuNP peak at $\sim 520 \mathrm{~nm}$ is not visible in this graph because of the scale of the absorbance used. 
(a)

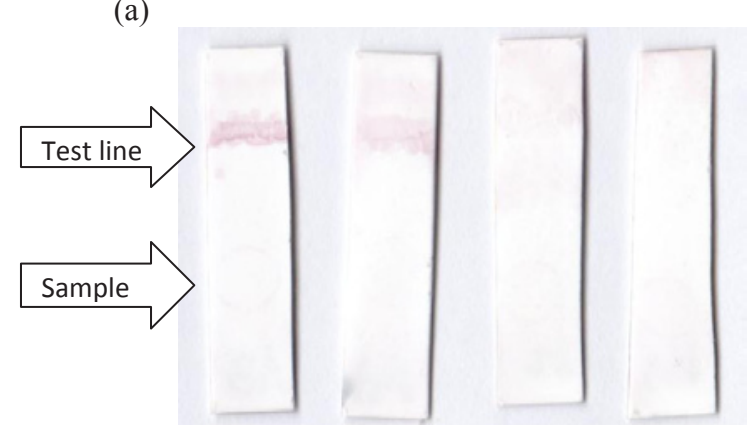

(b)

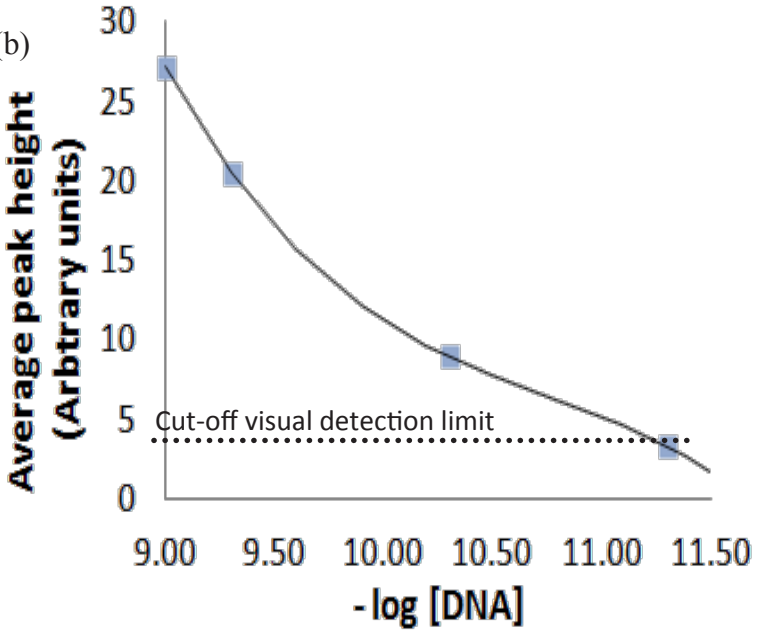

Figure 4: Optimization of the amount of captured DNA. (a) Test strips showing subsequent dilution of DNA immobilized onto the test strip. From left, (in pmol): $1000,500,50$ and 5. "Test" arrow indicates where the DNA was immobilized and "sample" arrow indicates where the AuNP-DNA was added. (b) Graph of the intensity of the red band in (a). The cut-off for visual detection is placed at 10 units as shown i.e., at 10 units, the red band is visually observable.

cannot be quantified using the peak at $256 \mathrm{~nm}$ in figure 2a because it interferes with the absorbance of dATP.

\section{Assembly and characterization of the lateral flow strip biosensor}

In a competitive binding assay, a complementary DNA strand (sequence 2) to the DNA sequence attached to the AuNP (sequence 1) is immobilized onto a part of the membrane called the test line. Then, a small amount of sample is added to the AuNP-DNA and the mixture is allowed to elute through the membrane. If the target DNA which is also the complementary strand of the bioconjugated DNA hybridizes with AuNP-DNA, then the AuNP-DNA can no longer be captured in the test line. In the absence of the target DNA, the AuNP-DNA is bound to the test line. When AuNP-DNA accumulates in the test line, the AuNP gives the characteristic purplish-red color.

Previous studies involving LFSB are usually non-competitive and involve longer probes [2-3], and/or multiple bioconjugation that involves one that binds to the target antigen and another that binds to the test line [26]. Competitive binding lessens the number of probes needed to the capture probe and the target DNA has the same sequence thereby making the detection simpler and cheaper. As a preliminary test for the feasibility of the work, it must be made sure that AuNP has no affinity towards the complementary (non-thiolated) DNA strand immobilized onto the membrane. It was confirmed that only when AuNP is bioconjugated to the complementary strand of the DNA immobilized will the red band appear signifying that the detection is due to the hybridization of complementary DNA strands and AuNP concentrated onto a small region.

\section{Hybridization experiments}

To maximize the efficiency of the test strip, it was first treated with a blocking buffer that prevents unselective binding of AuNP-DNA to other parts of the membrane. This increased the sensitivity of the method by making sure most, if not all, of the AuNP-DNA bound to the test line; thus, for the experiments henceforth, all test strips were pretreated with blocking buffer.

After pre-treatment, a series of test strips were created with different amounts of capture probe as shown in figure 4a. The intensity of the red band is graphed against the amount of probe present is shown in figure $4 \mathrm{~b}$. By inspection, the intensity of $\sim 10$ units is the minimum to create an unambiguous claim for the presence of a red band. Less than 10 units is too faint and may lead to highly uncertain reading. Given these limitations, the visual limit of detection is 50 pmol of DNA immobilized onto the test strip. Since the amount of captured AuNP-DNA is proportional to the intensity of the signal, a study was conducted to establish this relation. An excess of capture probe was striped onto the test line and a known amount of AuNP-DNA was allowed to elute through the membrane. It was safe to assume that all of the AuNP-DNAwas captured onto the test line. This is equal to the amount of AuNP since all free DNA was already washed away. The intensity of the band measured by optical densitometry was plotted against the concentration of the AuNP-DNA and a linear relationship was observed as in figure 5. Using the calibration curve, the 10 units' visual limit corresponds to $156 \mathrm{pmol}$ of AuNP-DNA.

In figure 6, a series of test strips are shown with decreasing concentration of target DNA spiked onto the sample in different matrices. PBS buffer was used in figure $6 \mathrm{a}$, while in figure $6 \mathrm{~b}$, a human blood sample is used as a matrix, and in figure $6 c$, an unrelated DNA is added to the matrix for both PBS and human blood, figure $6 \mathrm{~d}$ shows the graph of the intensity of the band versus the amount of DNA added. The mismatched DNA has a sequence that corresponds to that of Influenza A virus based on the study of Fouchier et al. [27]. At $10^{-8} \mathrm{M}$ of dengue DNA or higher, the decision is unambiguously positive. At $10^{-7} \mathrm{M}$, considering standard deviation, it may be reported as a false negative already. Since there is a greater chance for it to still be reported

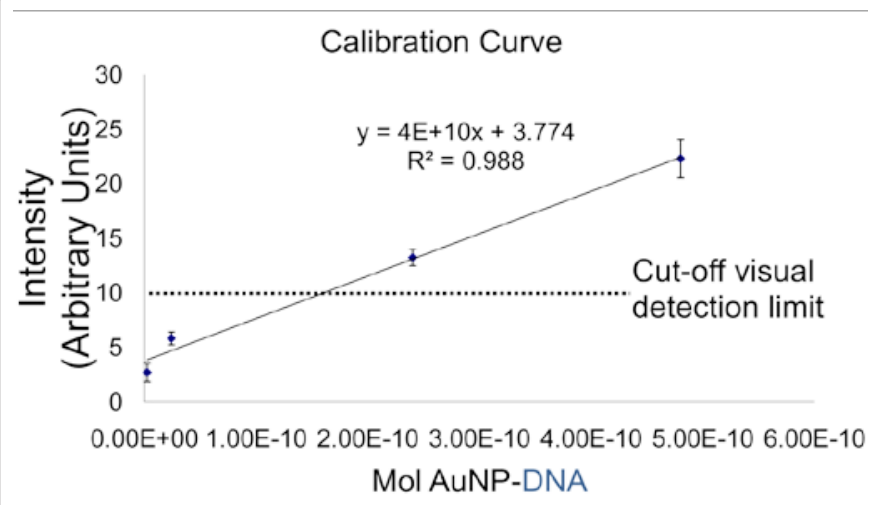

Figure 5: Calibration curve of the intensity of the red band against the amount of AuNP-DNA captured. A linear relationship is observed where the cutoff detection limit corresponds to 156 pmol of AuNP-DNA. 


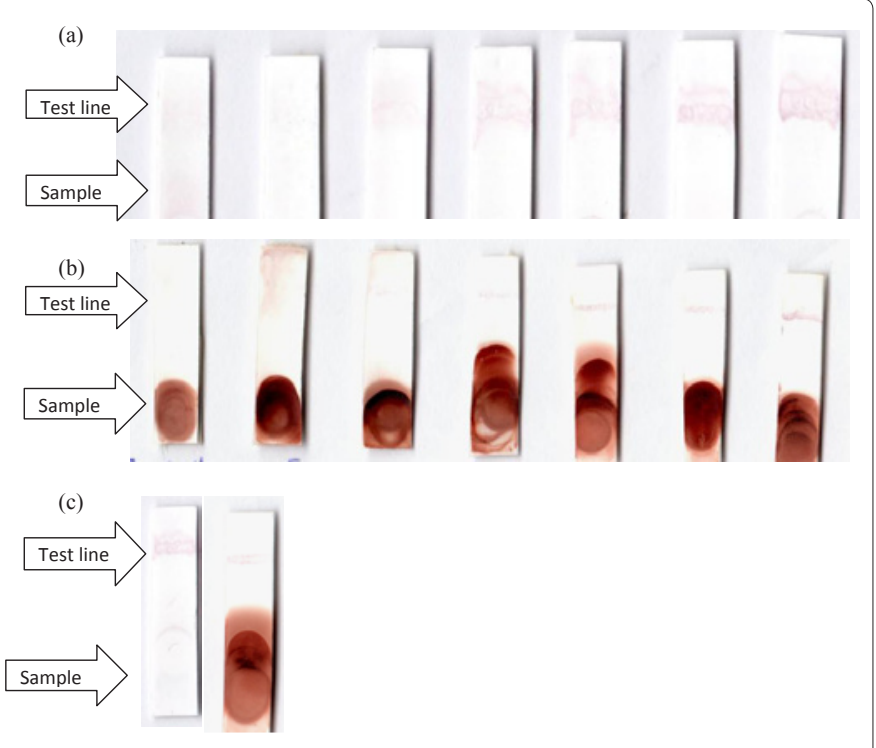

(d)

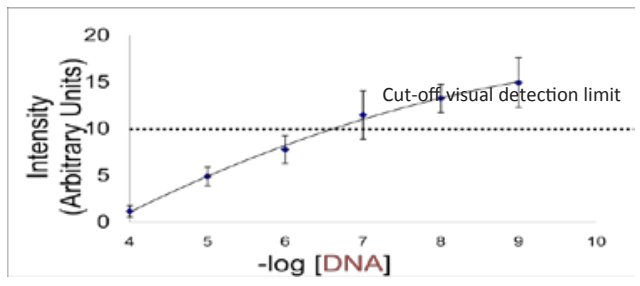

Figure 6: Sensitivity and selectivity studies. For (a) and (b): Serially-diluted synthetic dengue DNA was added (from left: $10^{-4}, 10^{-5}, 10^{-6}, 10^{-7}, 10^{-8}$, and $10^{-9}$ $\mathrm{M}$ dengue DNA) onto the AuNP-DNA mixture and added to a test strip with striped capture probe in PBS for (a) and healthy

human blood in (b). Selectivity is studied in (c) where a $10^{-4} \mathrm{M}$ mismatch DNA is added instead of dengue DNA in PBS and blood matrix. Both show a red band indicating a negative result. (d) shows a graph of the intensity of the red bands in (a) and (b).

as positive, the visual detection limit is therefore set at $10^{-7} \mathrm{M}$. The effect of the blood matrix and the mismatch DNA is negligible as shown in the same figure. The blood matrix is too large for the pore size of the nitrocellulose membrane so they are left in the lower part of the strip (Figure 6b). The mismatch DNA makes the intensity a little lighter than pure PBS solution but is still judged as unambiguously negative. Overall, the LFSB design is selective to dengue DNA sequence even in a blood sample matrix. Here, the LFSB is easier to use since no pretreatment of the blood sample is needed.

\section{Conclusion}

The study has shown a promising detection method that is selective to dengue viral RNA (DNA) in whole blood matrix using a lateral flow strip biosensor. The whole test is simple and can be done without technical background. Results are also visible within five minutes so this makes a feasible point-of-care detection device for dengue. This can be developed further into serospecific detection. Previous studies have shown the feasibility of multiple analytes in a single test strip [26] by adding test lines that correspond to the sequence of the serospecific region previously studied by Baeumner et al. [22]. Although the sensitivity $\left(10^{-7} \mathrm{M}\right)$ does not reach clinically relevant values $\left(10^{-15}-10^{-11} \mathrm{M}\right)$ for dengue viral DNA, a simple solidstate orthosilicate based [28] or magnetic nanoparticles-based (Kouassi 2006) pre-concentration step may be added, or stabilizers may be added to ensure 1:1 AuNP:DNA ratio [29] to improve the detection limit.

\section{Acknowledgments}

This work was made possible through the support of the Department of Science and Technology (DOST), Philippines and the Department of Chemistry of Ateneo de Manila University.

\section{References}

1. Liu J, Cao Z, Lu Y (2009) Functional nucleic acid sensors. Chem Rev 109 1948-1998.

2. Mao X, Ma Y, Zhang A, Zhang L, Zeng L, et al. (2009) Disposable nucleic acid biosensors based on gold nanoparticle probes and lateral flow strip. Anal Chem 81: $1660-1668$.

3. Glynou K, loannou PC, Christopoulos TK, Syriopoulou V (2003) Oligonucleotidefunctionalized gold nanoparticles as probes in a dry-reagent strip biosensor for DNA analysis by hybridization. Anal Chem 75: 4155-4160.

4. Xu H, Mao X, Zeng Q, Wang S, Kawde AN, et al. (2009) Aptamer-functionalized gold nanoparticles as probes in a dry-reagent strip biosensor for protein analysis. Anal Chem 81: 669-675

5. Baeumner AJ, Cohen RN, Miksic V, Min J (2003) RNA biosensor for the rapid detection of viable Escherichia coli in drinking water. Biosens Bioelectron 18: 405-413.

6. Yan Z, Zhou L, Zhao Y, Wang J, Huang L, et al. (2006) Rapid quantitative detection of Yersinia pestis by lateral-flow immunoassay and up-converting phosphor technology-based biosensor. Sensors and Actuators B: Chemical 119: 656-663.

7. Delmulle BS, De Saeger SM, Sibanda L, Barna-Vetro I, Van Peteghem CH (2005) Development of an immunoassay-based lateral flow dipstick for the rapid detection of aflatoxin B1 in pig feed. J Agric Food Chem 53: 3364-3368.

8. Zhang G, Wang X, Zhi A, Bao Y, Yang Y, et al. (2008) Development of a lateral flow immunoassay strip for screening of sulfamonomethoxine residues. Food Addit Contam Part A Chem Anal Control Expo Risk Assess 25: 413-423.

9. Huo Q (2007) A perspective on bioconjugated nanoparticles and quantum dots Colloids Surf B Biointerfaces 59: 1-10.

10. Posthuma-Trumpie GA, Korf J, van Amerongen A (2009) Lateral flow (immuno) assay: its strengths, weaknesses, opportunities and threats. A literature survey. Anal Bioanal Chem 393: 569-582.

11. Baeumner AJ, Schlesinger NA, Slutzki NS, Romano J, Lee EM, et al. (2002) Biosensor for dengue virus detection: sensitive, rapid, and serotype specific. Anal Chem 74: 1442-1448.

12. Poloni TR, Oliveira AS, Alfonso HL, Galvao LR, Amarilla AA, et al. (2010) Detection of dengue virus in saliva and urine by real time RT-PCR. Virol J 7: 22.

13. Usawattanakul W, Jittmittraphap A, Pramuan T, Siripanichgon K, Buchachar K, et al. (2002) Detection of Dengue Viral RNA in Patients' Sera by Nucleic Acid Sequence-Based Ampification (NASBA) and Polymerase Chain Reaction. Dengue Bulletin 26: 131-139.

14. Wu SJ, Lee EM, Putvatana R, Shurtliff RN, Porter KR, et al. (2001) Detection of dengue viral RNA using a nucleic acid sequence-based amplification assay. J Clin Microbiol 39: 2794-2798.

15. Parida M, Horioke K, Ishida H, Dash PK, Saxena P, et al. (2005) Rapid detection and differentiation of dengue virus serotypes by a real-time reverse transcription-loop-mediated isothermal amplification assay. J Clin Microbiol 43 : 2895-2903.

16. Fry SR, Meyer M, Semple MG, Simmons CP, Sekaran SD, et al. (2011) The diagnostic sensitivity of dengue rapid test assays is significantly enhanced by using a combined antigen and antibody testing approach. PLoS Negl Trop Dis 5: e1199.

17. Blacksell SD, Jarman RG, Bailey MS, Tanganuchitcharnchai A, Jenjaroen $K$ et al. (2011) Evaluation of Six Commercial Point-of-Care Tests for Diagnosis of Acute Dengue Infections: the Need for Combining NS1 Antigen and IgM/lgG Antibody Detection to Achieve Acceptable Levels of Accuracy. Clin. and Vacc. Immunol. 18: 2095-2101.

18. Vaughn DW, Green S, Kalayanarooj S, Innis BL, Nimmannitya S, et al. (1997) 
Citation: Yu HLL, Montesa CM, Rojas NRL, Enriquez EP (2012) Nucleic-Acid Based Lateral Flow Strip Biosensor via Competitive Binding for Possible Dengue Detection. J Biosens Bioelectron 3:128. doi:10.4172/2155-6210.1000128

Page 6 of 6

Dengue in the early febrile phase: viremia and antibody responses. J Infect Dis 176: 322-330.

19. Baeumner AJ, Pretz J, Fang S (2004) A universal nucleic acid sequence biosensor with nanomolar detection limits. Anal Chem 76: 888-894.

20. Chen LH, Wilson ME (2005) Non-Vector Transmission of Dengue and Other Mosquito-Borne Flaviviruses. Dengue Bulletin 29: 18-31.

21. Martin MN, Basham JI, Chando P, Eah SK (2010) Charged gold nanoparticles in non-polar solvents: 10 -min synthesis and 2D self-assembly. Langmuir 26 : 7410-7417.

22. Zhao W, Lin L, Hsing IM (2009) Rapid synthesis of DNA-functionalized gold nanoparticles in salt solution using mononucleotide-mediated conjugation. Bioconjug Chem 20: 1218-1222.

23. 23. Link S, El-Sayed MA (1999) Size and Temperature Dependence of the Plasmon Absorption of Colloidal Gold Nanoparticles. J Phys Chem B 103 4212-4217.

24. Oh E, Delehanty JB, Sapsford KE, Susumu K, Goswami R, et al. (2011) Cellular uptake and fate of PEGylated gold nanoparticles is dependent on both cellpenetration peptides and particle size. ACS Nano 5: 6434-6448.

25. Giljohann DA, Seferos DS, Patel PC, Millstone JE, Rosi NL, et al. (2007) Oligonucleotide loading determines cellular uptake of DNA-modified gold nanoparticles. Nano Lett 7: 3818-3821.

26. Litos IK, loannou PC, Christopoulos TK, Traeger-Synodinos J, Kanavakis E (2009) Multianalyte, dipstick-type, nanoparticle-based DNA biosensor for visual genotyping of single-nucleotide polymorphisms. Biosens Bioelectron 24: 3135-3139.

27. Fouchier RA, Bestebroer TM, Herfst S, Van Der Kemp L, Rimmelzwaan GF, et al. (2000) Detection of influenza A viruses from different species by PCR amplification of conserved sequences in the matrix gene. J Clin Microbiol 38 4096-4101.

28. Wen J, Guillo C, Ferrance JP, Landers JP (2006) DNA extraction using tetramethyl orthosilicate-grafted photopolymerized monolithic solid phase. Anal Chem 78: 1673-1681.

29. Taton TA (2002) Preparation of gold nanoparticle-DNA conjugates. Curr Protoc Nucleic Acid Chem. 